\title{
SINERGIA
}

REVISTA DO INSTITUTO DE CIÊNCIAS ECONÔMICAS, ADMINISTRATIVAS E CONTÁBEIS (ICEAC)

\section{NÍVEL DE CONHECIMENTO DOS PROFISSIONAIS CONTÁBEIS DE PERNAMBUCO ACERCA DA NORMA INTERNACIONAL DE CONTABILIDADE IFRS 16}

RAIMUNDO NONATO LIMA FILHO* MAYLANE ALVES DA SILVA*

\section{RESUMO}

Este estudo teve como objetivo analisar o nível de conhecimento e aplicação da IFRS 16 pelos profissionais contábeis de Pernambuco. Para atingir o objetivo da pesquisa, utilizou-se uma pesquisa descritiva, com abordagem do problema classificado como quantitativa, utilizando, como procedimento de coleta de dados, o survey. Através dos dados obtidos, analisaram-se as estatísticas descritivas das respostas, teste de normalidade e testes de correlações, permitindo, assim, a comparação de resultados por tipos de grupos como gênero, tempo de formação e tempo de atuação. De acordo com a pesquisa, percebeu-se que os contadores ainda não possuem conhecimento suficiente sobre a referida IFRS e, por isso. houve divergências no entendimento da norma pelos profissionais. Verificou-se ainda que, apesar da maioria dos participantes terem conhecimentos teóricos pertinentes às normas atuais, faz-se necessária a capacitação para colocar os novos procedimentos estabelecidos pelas normas em prática. O estudo contribuiu para identificar que a formação no ensino superior e o tempo de atuação na área contábil não são suficientes para formar o profissional contábil e que a frequente atualização, através da educação continuada e de cursos de atualização, são fundamentais para que os contadores estejam informados pelas mudanças impostas pelas Normas de Contabilidade.

Palavras-chaves: Contabilidade; IFRS; Normas Contábeis.

\section{ABSTRACT}

This study aimed to analyze the level of knowledge and application of IFRS 16 by accounting professionals from Pernambuco. To achieve the research objective, a descriptive research was used, with approach to the problem classified as quantitative, using the survey as the data collection procedure. Through the obtained data, the descriptive statistics of the responses, normality test and correlation tests were analyzed, thus allowing the comparison of results by types of groups such as gender, time of formation and time of performance. According to the survey, it was noticed that accountants still do not have sufficient knowledge about IFRS, and therefore there were divergences in the understanding of the Standard by professionals. It was also found that, despite the majority of the participants having theoretical knowledge pertinent to the current standards, training is needed to put the new procedures established by the standards into practice. The study contributed to identify that training in higher education and the time working in the accounting area is not enough to train the accounting professional, and that frequent updating through continuing education and refresher courses are essential for accountants to be informed by changes imposed by the Accounting Standards.

Keywords: Accounting; IFRS; Accounting Standards.

Recebido em: 23-12-2020 Aceito em: 23-04-2021

\section{INTRODUÇÃo}

As IFRS - International Financial Reporting Standards - são normas que foram criadas com o objetivo de fornecer para as empresas um conjunto normativo que deve ser empregado para a elaboração e para a divulgação das demonstrações e das políticas contábeis existentes entre os países, melhorando a estrutura conceitual, proporcionando qualidade nas interpretações das demonstrações financeiras (MATOS; NIYAMA, 2018).

Com a Lei 11.638/2007, o Brasil passou a introduzir importantes conceitos, tendo sido adaptados conceitos legais bastante utilizados em economias mais desenvolvidas. Foram trazidas inovações tanto para as demonstrações contábeis quanto para as práticas contábeis, visto que essas normas são baseadas muito mais em princípios do que em regras (SAIKI; ANTUNES, 2010).

Consequentemente, essa abordagem traz impactos substanciais para a profissão contábil, dado que o

\footnotetext{
"Doutor em Controladoria e Contabilidade pela Universidade de São Paulo (USP) e Doutor em Administração pela Universidade Federal da Bahia (UFBA), Pós-Doutorado pela Universidade Federal da Paraíba (UFPB). Professor da Universidade de Pernambuco (UPE) e da Autarquia Educacional do Vale do São Francisco (AEVSF). E-mail: rnlfilho@gmail.com

" Graduada em Ciências Contábeis pela Faculdade de Ciências Aplicadas e Sociais de Petrolina (FACAPE).
} 
contador passa a exercer muito mais sua capacidade de julgamento do que no passado, com reflexões sobre o status da profissão no Brasil. As inovações trazidas por essa lei, também, causaram algumas mudanças, especialmente, para os contadores, gestores, auditores e para o mercado de capitais; este último considerado um importante usuário da informação contábil divulgada (DANTAS et al., 2017).

Entretanto, pode-se afirmar que as mudanças introduzidas buscam aprimorar a qualidade da informação contábil, tendo como foco principal a sua utilidade para o usuário dessa informação; as melhorias visando aprimorar a compreensibilidade, a relevância, a confiabilidade e a comparabilidade das informações divulgadas - características qualitativas da informação contábil e as tornam úteis (BRASIL, 2008).

A necessidade de implantação das IFRS, no Brasil, deriva, principalmente, de questões relacionadas à padronização das normas internacionais de contabilidade, bem como do incentivo ao progresso de investimentos estrangeiros no País (DANTAS et al., 2017). Uma recente pesquisa revela que algumas companhias listadas, nas 85 principais bolsas de valores, adotam a padronização contábil das IFRS (SILVA, 2013). Além disso, das companhias que não empregam as normas, mais de $80 \%$ são listadas nas bolsas da China, da Índia, do Japão e dos Estados Unidos (GIROTTO, 2017).

O presente estudo aborda a IFRS 16, que atualiza a IAS 17, adaptando diversas formas de aplicar a norma, a maneira de contabilização acerca do arrendamento. A IFRS 16, também, teve sua aplicabilidade obrigatória a partir do ano de 2019 (MATOS; NIYAMA, 2018).

Com essa obrigatoriedade, as empresas precisaram reavaliar os contratos já existentes para realizar a transição, seguindo, portanto, a IFRS 16, cujas mudanças de procedimentos incluem o reconhecimento de um ativo de direito de uso e um passivo de arrendamento (DANTAS et al., 2017). Por conta de tais mudanças, existem, ainda, lacunas na academia acerca dessa norma.

A classe contábil não segue um padrão uniforme, uma vez que existem profissionais na área que já tem um padrão de procedimentos adotados e preferem não aderir às mudanças ocorridas que levem a uma adaptação em sua atuação. Em razão disso, surgiu o seguinte questionamento: qual o nível de conhecimento dos profissionais contábeis quanto a IFRS 16? Tem como objetivo apontar o nível de conhecimento da IFRS 16 pelos profissionais contábeis de Pernambuco.

Nesse segmento, o presente estudo se justifica pela necessidade de avaliar o cenário atual, sobretudo, porque os contabilistas têm o dever de conhecer a IFRS 16 e de aplicar correta e integralmente, uma vez que, impostas pela lei, foram criadas para uniformizar todo o sistema contábil, facilitando a análise das informações. Para tanto, é preciso estar habilitado para o trabalho que desempenham, restando comprovada a confiabilidade das demonstrações contábeis do grupo de profissionais estudados.

A análise é relevante à medida que se espera que esta pesquisa contribua tanto com o meio acadêmico quanto com o mercado de capitais, com os conselhos de administração e com os acionistas, órgãos de regulação e controle sobre implicações referentes ao processo de convergência das normas internacionais de contabilidade no Brasil e ao aperfeiçoamento dos profissionais contábeis a partir da adoção dessas normas.

\section{REVISÃO DE LITERATURA}

\subsection{Normas Internacionais de Contabilidade - IFRS}

De acordo com Ribeiro (2017), o surgimento das Normas IFRS ocorreu a partir do conceito de convergência contábil, em meados dos anos de 1950, pois houve um aumento de investimento entre países no mercado de capitais, fruto da integração econômica pós $2^{\text {a }}$ Guerra Mundial. Com o aumento do fluxo de capital, percebeu-se que as normas contábeis divergiam entre os países ao fazer uma comparação das demonstrações contábeis de empresas de diferentes países, o que dificultava a análise das demonstrações finais (DANTAS et al., 2017). Nesse contexto, foi fundado, em 1973, o International Accounting Standards Commitee (IASC), objetivando a criação de normas com conceitos mais gerais, denominadas de International Accounting Standards (IAS). O intuito era de harmonizar as normas contábeis dos diferentes países do mundo, diminuindo as diferenças existentes nas práticas contábeis entre esses países e aumentando a comparabilidade de suas demonstrações financeiras (MEIRELLES; VENDRUSCOLO, 2017).

Campanha e Santos (2020) afirmam que, em 2001, o IASC passou por uma reestruturação, originando o International Accounting Standards Board (IASB), com a finalidade de substituir as divergentes normas contábeis nacionais por um padrão contábil único, através das IFRS. Com essa adoção, permitiu-se aumentar da comparabilidade das demonstrações financeiras de diferentes empresas ao redor do mundo. A partir de pesquisas recentes como as de Dantas et al. (2017), Meirelles e Vendruscolo (2017) e Zortea et al. (2017), concluiu-se que empresas que aplicam as IAS elevaram o padrão contábil, superando aquelas que utilizam padrões domésticos. Notou-se, também, um menor gerenciamento de resultados e o reconhecimento de perdas em tempo hábil na adoção das normas IFRS no âmbito.

Para Araújo e Zittei (2018), a visão geral sobre a importância que favorece a adesão das normas 
internacionais defende que as IFRS representam um padrão contábil mais avançado, se comparado aos GAAP's domésticos. Para complementar, entende-se que a convergência para um padrão contábil unificado melhora a comparabilidade das companhias. Sendo assim, as normas internacionais de contabilidade objetivam aprimorar o ambiente informacional da empresa, contribuindo para a redução de seu custo de capital. Becker (2017) reforça que um padrão contábil harmônico e de alta qualidade, alcançado pelas IFRS, pode trazer grandes benefícios para as empresas, como o aumento de investidores de outros estados adaptados ao IFRS; a redução do custo de capital com o aumento na demanda por investimentos nas empresas estrangeiras e o aumento da liquidez do mercado de capitais.

Para Silva (2013), os efeitos em adotar o IFRS, nas empresas brasileiras de capital aberto, estão no aumento na qualidade da informação contábil, além da redução de custos de capital próprio.

Dessa forma, percebe-se que a implantação de normas IFRS, em diferentes territórios no mundo, gera um amplo benefício para os que adotaram, pois há redução das diferenças nas normas contábeis entre uma jurisdição e outra.

O International Accounting Standards Board (IASB) tem sido amplamente responsável por desenvolver um conjunto de padrões de relatórios financeiros que possam ser usados internacionalmente. A necessidade para a convergência das IFRS foi apoiada pela afirmação de que um único conjunto de padrões contábeis de alta qualidade é um meio importante, por exemplo, de melhorar a comparabilidade dos relatórios financeiros e reduzir o custo de sua preparação e análise (DOUPNIK; PERERA, 2012).

Um dos grandes objetivos das IFRS, que pode ser também entendido como uma vantagem para a contabilidade brasileira, é o fato de que sua adoção permitiu que a informação contábil ficasse mais acessível, sem abrir mão de sua linguagem contábil, já que as demonstrações de todos os países que adotam essas normas têm a mesma estrutura e utilizam, de forma básica, os mesmos mecanismos para contabilização dos fatos que modificam o patrimônio das entidades (CAMPANHA; SANTOS, 2020).

Em síntese, Gonçalves et al. (2016) afirmam que as demonstrações contábeis são a principal fonte de informações econômico-financeiras das empresas, para uma ampla gama de usuários em seus processos decisórios. E que a normatização contábil tem por objetivo garantir que essas informações divulgadas sejam compreensíveis, relevantes, confiáveis e comparáveis, ou seja, úteis para o processo decisório dos usuários, principalmente, para aqueles que são externos à empresa.

Segundo Cruz et al. (2011), essa modificação não será facilmente absorvida pelas organizações, o que é complementar à visão de Tay e Parker (1990), em que, caso não sejam devidamente punidas, as empresas que não aplicarem as mudanças ou a adoção sem preparo prévio, aos novos padrões, podem prejudicar os usuários da informação contábil. Em dados de outro estudo, Fonteles, Oliveira e Almeida (2011) afirmam que uma das principais razões que dificultam a não adequação contábil se deve ao regime legal que cada país possui, aos altos custos para a atualização.

Algumas dificuldades são enfrentadas com a adoção do processo de convergência contábil. Niyama (2009) destaca que os critérios de avaliação, apropriação e classificação contábil, determinados pela legislação fiscal, geram uma dificuldade maior para que a harmonização aconteça.

\subsection{IFRS 16 - Leasing}

As locações representam uma atividade importante para distintas entidades, sendo um meio de obter financiamento, acesso a ativos e reduzir a exposição de uma entidade aos riscos de propriedade de ativos. Nesse sentido, é importante que os utilizadores das demonstrações financeiras tenham um quadro completo e compreensível das atividades das locações de uma entidade (International Financial Reporting Standards (IFRS) Foundation, 2013).

Os modelos contabilísticos existentes na International Accounting Standards (IAS) 17 exigiam que os locatários e os locadores classificassem as suas locações como locações financeiras ou como locações operacionais, com distintos modelos de contabilização. Tal distinção não satisfazia às necessidades dos investidores, na medida em que a dependência da qualificação das locações resultaria em distintos tratamentos nas demonstrações financeiras, sendo, alguns casos, apresentados no balanço e, em outros, apenas refletidos na demonstração dos resultados do período em que as rendas são contabilizadas como gastos (Lloyd, 2016). Como resultado dessa divergência, os investidores, frequentemente, ajustavam as demonstrações financeiras dos locatários para reconhecer ativos e passivos que se encontravam "fora do balanço", procedendo ao ajustamento de indicadores relevantes na análise econômico-financeira das entidades (IFRS Foundation, 2016a).

Em janeiro de 2016, o International Accounting Standards Boarding (IASB) emitiu nova norma sobre a contabilização do leasing operacional, o International Financial Reporting Standard 16 (IFRS 16). As empresas que realizam esse tipo de operação devem atender, obrigatoriamente, à norma a partir de $1^{\circ}$ de janeiro de 2019, o que permite um período de adaptação e de uma análise prévia do impacto que a contabilização do leasing operacional causará na instituição. Há duas formas de operação de leasing, ou 
como chamado no Brasil, arrendamento mercantil. Ambos se referem a um contrato entre duas partes, em que uma (arrendadora) oferece os direitos de uso de um bem a outra parte (arrendatária). No entanto, existem alguns critérios para que a operação seja classificada em financeira ou operacional.

Nesse sentido, a IFRS 16, então aprovada, elimina a tradicional classificação das locações como operacionais ou financeiras sob o ponto de vista dos locatários, introduzindo um modelo único de contabilização. Tal modelo reflete que as locações resultam na obtenção de um direito de usar o ativo por uma entidade no princípio da locação, em contrapartida de um passivo resultante da obrigação (financiamento obtido) de pagar um conjunto de rendas ao longo do tempo. Nesse sentido, significa, em termos práticos, a adoção, por parte dos locatários, de um tratamento único e similar ao já previsto na atual IAS 17 para as locações financeiras, com algumas exceções.

O principal motivo da escolha do leasing operacional, ou arrendamento operacional, em detrimento do leasing financeiro, se deve ao fato de que aquele não é contabilizado em contas patrimoniais, ou seja, não é apresentado no balanço patrimonial. Suas contraprestações são registradas, diretamente, no resultado. Sendo assim, não são reconhecidos como um direito de uso no ativo, nem as contraprestações como uma obrigação no passivo.

No entanto, a norma vigente, IAS 17, que permite as duas formas de contabilização para cada tipo de leasing, gera discussões e apresenta certa contradição na avaliação da situação econômica e financeira da entidade. Uma única contabilização, como normatizado no IFRS 16, acarretará em uma maior transparência, bem como aumentará a comparabilidade na empresa e, também, com as demais.

Com a introdução da IFRS 16, norma que substituirá a atual IAS 17 de mesma designação (Leases) e interpretações relacionadas, tal recurso deixa de ser necessário, na medida em que as duas demonstrações financeiras (balanço e anexo) passarão a apresentar informação sobre tais operações, isto é, sobre os contratos de locação realizados pelos locatários. Nesse sentido, a IFRS 16, então aprovada, elimina a tradicional classificação das locações como operacionais ou financeiras sob o ponto de vista dos locatários, introduzindo um modelo único de contabilização. Tal modelo reflete que as locações resultam na obtenção de um direito de usar o ativo por uma entidade no princípio da locação por contrapartida de um passivo resultante da obrigação (financiamento obtido) de pagar um conjunto de rendas ao longo do tempo.

A IFRS 16 é aplicável aos períodos que se iniciem em ou após 1ำ de janeiro de 2019, não tendo sido endossada, até a data, pela União Europeia. Pretende-se que tais alterações aumentem a transparência do relato financeiro, indo ao encontro dos interesses dos investidores e de outros acionistas, melhorando, consequentemente, o processo de tomada de decisão baseada nessa informação (IFRS FOUNDATION, 2016; LLOYD, 2016).

Nas palavras do IFRS Foundation (2016), na base do desenvolvimento conjunto da norma entre o International Accounting Standards Board (IASB) e o Financial Accounting Standards Board (FASB), encontrava-se, de fato, uma preocupação única no que concerne à falta de transparência para as distintas partes interessadas no relato financeiro, incluindo os investidores, no que diz respeito às operações de locação. O processo que resultou na emissão da IFRS 16 passou por diversas etapas que incluíram três consultas públicas sobre as propostas apresentadas pelo IASB, nomeadamente: a emissão de um Discussion Paper (DP) em 2009; a emissão do primeiro Exposure Draft (ED) em 2010; e, por fim, um ED revisto, em 2013. Os processos foram detalhadamente discutidos os custos de implementação e outras atividades de divulgação (IFRS Foundation, 2016). Um grupo de trabalho foi ainda criado pelo IASB e pelo FASB, no sentido de, adicionalmente, obter-se acesso à experiência prática e expertise nessa matéria (IFRS FOUNDATION, 2016).

Importante observar que a norma IFRS 16 não se restringe aos arrendamentos mercantis, pois ela inclui todos os tipos de contratos que (dentro de certas condições) transferem o direito de uso de um ativo, o que pode incluir, como exemplos: locações e aluguéis de máquinas, equipamentos, veículos, imóveis; direitos de franquias; direito de uso de propriedade rural etc. Ou seja, a norma é bem abrangente e pode ser enquadrada em diversas empresas e segmentos.

\section{PROCEDIMENTOS METODOLÓGICOS}

A presente pesquisa procurou apontar o nível de conhecimento e aplicação da IFRS 16 pelos profissionais contábeis de Pernambuco. Esta pesquisa tem natureza descritiva, a partir da qual é possível analisar um determinado grupo pertecente à amostra do estudo. Ainda acerca da classificação do estudo, classifica-se, quanto à abordagem do problema, como uma pesquisa quantitativa, já que se sentiu a necessidade de identificar opiniões acerca do assunto da pesquisa, através de uma amostra que representasse, estatisticamente, um universo.

O universo da pesquisa é composto por 15.600 profissionais contábeis, com inscrição no Conselho Regional de Contabilidade (CRC) no estado de Pernambuco. A escolha do Estado DE Pernambuco se deu pela representatividade na classe contábil que o CRC-PE tem para o país, além da conveniência e da 
acessibilidade. Desses 15.600 profissionais, obtiveram-se respostas dos questionários, apenas de 109 profissionais.

Quanto ao instrumento de pesquisa adotado para a elaboração do trabalho, utilizou-se o questionário aplicado aos profissionais contabilistas que exercem suas atividades em escritórios ou que estejam ativamente inscritos no Conselho Regional de Contabilidade de Pernambuco (CRC-PE).

O questionário foi desenvolvido e aplicado a fim de colher informações que seriam úteis para o objetivo desta pesquisa. A aplicação do questionário foi efetuada no período julho a agosto de 2020 , através de formulário on-line. Foi desenvolvido em partes, em que cada uma das partes buscava selecionar determinado tipo de informação. Foram elaboradas perguntas e alocadas de modo segregado em que o respondente facilmente interpretasse.

A primeira parte do questionário visou analisar o perfil dos respondentes, identificando gênero, tempo de profissão, ano de formação e atuação. A segunda parte do questionário foi composta por questões especificas acerca do conhecimento por parte desses profissionais no que tange à IFRS 16, que aborda sobre o arrendamento, abordando, assim, questões sobre a contabilização do contrato, riscos inerentes ao uso do bem, valor residual e conhecimento acerca dos conceitos apresentados no Pronunciamento Técnico CPC 06, que é considerada a mesma norma da IFRS 16.

Com relação ao tratamento estatístico dos dados obtidos, a primeira fase buscou apresentar as estatísticas descritivas das respostas; a segunda fase visou apresentar o teste de normalidade dos dados e a terceira fase apresentou os testes de correlação, e, por fim, a comparação das notas e do perfil dos respondentes.

\section{ANÁLISE DOS RESULTADOS}

As respostas recolhidas foram, então, classificadas em função dos grupos de respondentes. A referida classificação procura captar o conhecimento de profissionais contábeis, interesses particulares no tema em análise (IFRS 16). A amostra foi constituída, inicialmente, por 109 profissionais, tendo-se excluído um número de respondentes por não ter sido possível identificar qualquer posicionamento específico a pelo menos uma das questões levantadas.

A Tabela 1 apresenta as características da amostra no quesito gênero, levando em consideração a amostra de 109 respondentes:

Tabela 1 - Gênero

\begin{tabular}{l|r|r}
\hline Gênero & Fi & \multicolumn{2}{|c}{ FI \% } \\
\hline Masculino & 44 & $40,40 \%$ \\
\hline Feminino & 65 & $59,60 \%$ \\
\hline Total & $\mathbf{1 0 9}$ & $\mathbf{1 0 0 \%}$ \\
\hline
\end{tabular}

Fonte: Dados da Pesquisa (2020)

Legenda: $\mathrm{Fi}$ = frequência, $\mathrm{Fl} \%$ = frequência percentual

A Tabela 1 demonstra que a maior parte dos profissionais pertencentes à amostra são do sexo feminino (cerca de 60\%), enquanto que, aproximadamente, $40 \%$ são do sexo masculino, atestando, assim, a mudança de paradigma na profissão contábil que hoje tem uma presença feminina significativa, conforme o que atesta Mota e Souza (2012), através de uma pesquisa acerca da evolução da mulher na contabilidade.

As mulheres, hoje, representam $42 \%$ dos profissionais registrados no País, números que vêm crescendo continuamente. As mulheres já são maioria nos cursos de Ciências Contábeis, que apresentaram, em 2015, 209 mil matrículas de estudantes do sexo feminino, ou 58\% do total de 358 mil matrículas. Este crescimento se reflete, cada vez mais, nas ações das entidades contábeis. Um exemplo é a decisão do Conselho Federal de Contabilidade (CFC) de colocar a designação "contadora" nas novas carteiras de identidade profissional. Até então, a carteira trazia, apenas, a designação "contador", independente do gênero.

Questionou-se, ainda, sobre o tempo de profissão dos respondentes e, conforme os dados, obtiveramse os seguintes achados, conforme Tabela 2:

Tabela 2 - Tempo de Profissão

\begin{tabular}{c|c|c}
\hline Tempo de Profissão & $\mathbf{F i}$ & $\mathbf{F l} \%$ \\
\hline 2 a 4 anos & 53 & 48,60 \\
\hline 5 a 7 anos & 31 & 28,40 \\
\hline 8 a 10 anos & 13 & 11,90 \\
\hline 11 anos acima & 12 & 11 \\
\hline Total & 109 & 100 \\
\hline
\end{tabular}

Fonte: Dados da Pesquisa (2020)

Legenda: $\mathrm{Fi}$ = frequência, $\mathrm{Fl} \%$ = frequência percentual 
Nota-se que o maior número de profissionais atuantes possui entre 2 e 4 anos, ou seja, são profissionais recentes no mercado de trabalho, enquanto $28,4 \%$ possui 5 a 7 anos de profissão, e $11,9 \%$ possuem 8 a 10 anos de profissão, e, apenas, $12 \%$ possuem mais de 11 anos. Através desses dados, percebeu-se que a maior parte dos profissionais tem conhecimento recente acerca das normas, haja vista que o processo de convergência às normas internacionais de contabilidade no Brasil iniciou-se no ano de 2008.

Dando sequencia à análise de tempo de profissão por parte dos respondentes, buscou-se identificar o ano de formação, conforme apresentado na Tabela 3:

Tabela 3 - Ano de Formação

\begin{tabular}{l|c|c}
\hline \multicolumn{1}{c|}{ Ano } & Fi & $\mathbf{F l} \%$ \\
\hline 1983 & 1 & 0,9 \\
\hline 1988 & 2 & 1,8 \\
\hline 1990 & 1 & 0,9 \\
\hline 2001 & 1 & 0,9 \\
\hline 2004 & 1 & 0,9 \\
\hline 2005 & 2 & 1,8 \\
\hline 2006 & 1 & 0,9 \\
\hline 2008 & 3 & 2,8 \\
\hline 2009 & 1 & 0,9 \\
\hline 2010 & 4 & 3,7 \\
\hline 2011 & 2 & 1,8 \\
\hline 2012 & 4 & 3,7 \\
\hline 2014 & 6 & 5,5 \\
\hline 2015 & 8 & 7,3 \\
\hline 2016 & 14 & 12,8 \\
\hline 2017 & 16 & 14,7 \\
\hline 2018 & 14 & 12,8 \\
\hline 2019 & 13 & 11,9 \\
\hline 2020 & 11 & 10,1 \\
\hline Ausente & 3 & 2,8 \\
\hline Total & 1 & 0,9 \\
\hline
\end{tabular}

Fonte: Dados da Pesquisa (2020)

Legenda: $\mathrm{Fi}$ = frequência, $\mathrm{Fl} \%$ = frequência percentual

Entre 2000 e 2006, houve poucos profissionais formados. Dos respondentes da pesquisa, a formação dos profissionais ocorreu, em sua maioria, entre 2015 e 2019, atingindo $62 \%$ do total, um dos participantes não apresentou o ano de formação e, por isso, foi considerado como dado ausente.

Além dos conhecimentos técnicos essenciais, o Contador da atualidade precisa, também, desenvolver habilidades relativas à comunicação, às relações humanas e à administração, criando um balanceamento adequado entre a formação teórica e experiência prática. De forma ainda mais fundamental, o treinamento deve, doravante, ser baseado em dois polos: educação inicial e educação continuada. Tabela 4

Dentre os participantes da pesquisa, buscou-se, ainda, verificar qual a devida atuação, conforme

Tabela 4 - Atuação

\begin{tabular}{l|c|c}
\hline Atuação & $\mathbf{F i}$ & $\mathbf{F l \%}$ \\
\hline Sócio da(empresa/(do) escritório contábil & 31 & 28 \\
\hline Autônomo & 46 & 42 \\
\hline Responsável/empregado (a) de área contábil & 32 & 29 \\
\hline Total & 109 & 100 \\
\hline
\end{tabular}

Fonte: Dados da Pesquisa (2020)

Legenda: $\mathrm{Fi}$ = frequência, $\mathrm{FI} \%$ = frequência percentual

É visto que a grande maioria, equivalente a $42 \%$, é autônoma na área da contabilidade, enquanto $28 \%$ são considerados sócios em escritório contábil, e $29 \%$ são empregados ou supervisores de departamento contábil. 
De um modo geral, a Tabela 5 apresenta os dados da estatística descritiva do perfil dos participantes da pesquisa:

Tabela 5 - Estatísticas Descritivas - Perfil dos Profissionais Contábeis

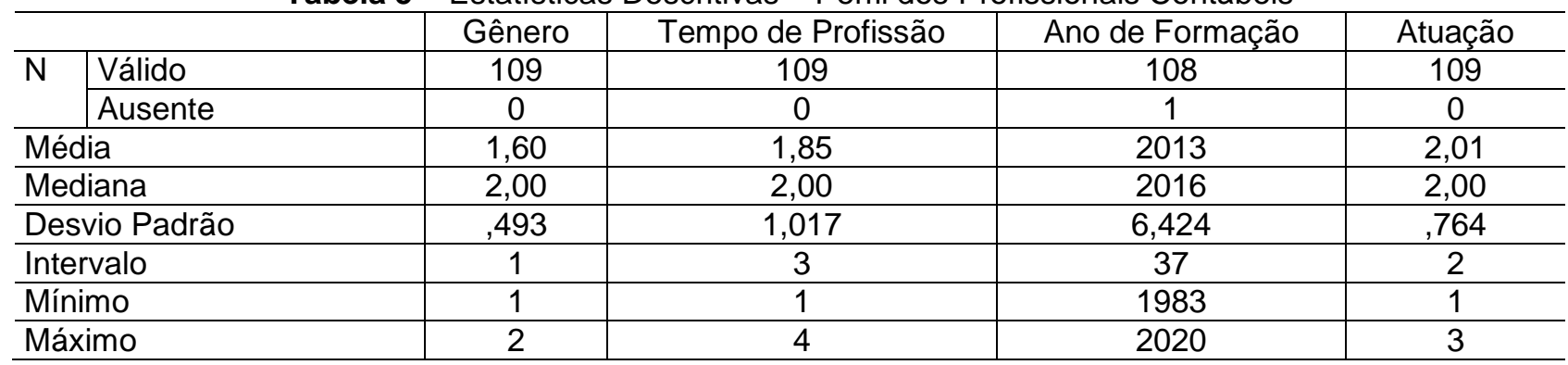

Fonte: Dados da Pesquisa (2020)

Como já apresentado anteriormente, o tempo de profissão, por parte dos profissionais, é de, aproximadamente, 2 anos, conforme média apresentada na estatística descritiva. Os anos de formação predominante se concentram entre 2013 e em anos posteriores, e o tempo de atuação, por parte dos profissionais, é, em média, de 1 ano, coincidindo, assim, com o tempo de profissão deles.

Como o objetivo da pesquisa é verificar sobre a percepção dos profissionais sobre a norma de arrendamento IFRS 16, buscou-se identificar o grau de conhecimento dos contadores acerca dos procedimentos que devem ser adotados no que diz respeito ao arrendamento.

Um dos questionamentos realizados acerca da IFRS 16 foi sobre como é realizada a contabilização do contrato, utilizando a norma, cujos dados foram ilustrados na Tabela 6:

Tabela 6 - Contabilização do contrato conforme IFRS 16

\begin{tabular}{c|c|c}
\hline Alternativas & $\mathbf{F i}$ & $\mathbf{F I} \%$ \\
\hline a) resposta correta & 12 & 11,0 \\
\hline b) & 10 & 9,2 \\
\hline c) & 73 & 67,0 \\
\hline d) & 3 & 2,8 \\
\hline Total & 11 & 10,1 \\
\hline
\end{tabular}

Fonte: Dados da Pesquisa (2020)

Legenda: $\mathrm{Fi}$ = frequência, $\mathrm{FI} \%$ = frequência percentual

Conforme questionário aplicado aos profissionais, notou-se que apenas 12 profissionais acertaram a resposta dessa questão, afirmando que, para a devida contabilização do contrato, é necessário abranger todos os custos de benfeitorias realizadas em bens alugados.

Outro questionamento realizado foi sobre a operação de arrendamento mercantil e sobre a transferência dos riscos pertinentes ao uso do bem arrendado conforme Tabela 7:

Tabela 7 - Transferência dos riscos inerentes ao uso do bem arrendado

\begin{tabular}{c|c|c}
\hline Alternativas & Fi & Fl\% \\
\hline a) & 9 & 8,3 \\
\hline b) resposta correta & 79 & 72,5 \\
\hline c) & 3 & 2,8 \\
\hline d) & 8 & 7,3 \\
\hline e) & 10 & 9,2 \\
\hline Total & $\mathbf{1 0 9}$ & $\mathbf{1 0 0 , 0}$ \\
\hline
\end{tabular}

Fonte: Dados da Pesquisa (2020)

Legenda: $\mathrm{Fi}$ = frequência, $\mathrm{Fl} \%$ = frequência percentual

Ao questionar sobre a denominação do procedimento de transferência do risco inerente ao uso do bem arrendado, como obsolescência tecnológica, desgastes etc, 79 respondentes marcaram a alternativa correta, que apresentava como resposta Arrendamento Mercantil Financeiro, ou seja, mais da metade dos profissionais conseguiram identificar o conceito correto.

Perguntou-se, ainda, sobre como deveriam ser contabilizadas as contraprestações dos contratos de arrendamento mercantil operacional na escrituração contábil do arrendatário, e foram obtidos os seguintes dados conforme Tabela 8: 
Tabela 8 - Contabilização das contraprestações dos contratos de arrendamento mercantil operacional nas demonstrações do arrendatário

\begin{tabular}{c|c|c}
\hline Alternativas & $\mathbf{F i}$ & $\mathbf{F l} \%$ \\
\hline a) & 8 & 7,3 \\
\hline b) resposta correta & 74 & 67,9 \\
\hline c) & 7 & 6,4 \\
\hline d) & 6 & 5,5 \\
\hline e) & 14 & 12,8 \\
\hline Total & $\mathbf{1 0 9}$ & $\mathbf{1 0 0 , 0}$ \\
\hline
\end{tabular}

Fonte: Dados da Pesquisa (2020)

Legenda: $\mathrm{Fi}$ = frequência, $\mathrm{FI} \%$ = frequência percentual

Dos 109 profissionais, 74 presentaram a alternativa correta que afirmava que as contabilizações pertinentes às contraprestações dos contratos de arrendamento mercantil devem ser realizadas diretamente no resultado, e não em contas pertencentes ao balanço patrimonial. Porém, ainda foi um percentual considerável de profissionais que não souberam responder sobre a devida contabilização, e cerca de $12,8 \%$ da amostra não sabiam a resposta correta da questão.

Ao perguntar sobre o valor residual garantido em um arrendamento mercantil financeiro, perceberamse os seguintes dados conforme Tabela 9:

Tabela 9 - Valor residual garantido no arrendamento mercantil financeiro

\begin{tabular}{c|c|c}
\hline Alternativas & $\mathbf{F i}$ & $\mathbf{F I} \%$ \\
\hline a) resposta correta & 72 & 66,1 \\
\hline b) & 14 & 12,8 \\
\hline c) & 4 & 3,7 \\
\hline d) & 7 & 6,4 \\
\hline e) & 12 & 11,0 \\
\hline Total & $\mathbf{1 0 9}$ & $\mathbf{1 0 0 , 0}$ \\
\hline
\end{tabular}

Fonte: Dados da Pesquisa (2020)

Legenda: $\mathrm{Fi}$ = frequência, $\mathrm{Fl} \%$ = frequência percentual

A IFRS 16 conceitua que o valor residual de um arrendamento mercantil financeiro é a parcela do valor residual do bem arrendado que seja garantida pelo arrendatário ou por alguém a ele relacionado ao arrendador. Dos profissionais que responderam ao questionário, 72 marcaram a alternativa correta, cerca de $66 \%$ da amostra, porém, ainda, foi significativo o percentual de profissionais que não souberam responder (11\%).

Sabe-se que o Brasil vem passando pelo processo de convergência aos padrões internacionais, assim, adaptando as Normas Internacionais ao País. A Tabela 10 apresenta os dados referentes à contabilização de um bem arrendado:

Tabela 10 - Contabilização do arrendamento mercantil de acordo com as normas brasileiras

\begin{tabular}{c|c|c}
\hline Alternativas & $\mathbf{F i}$ & $\mathbf{F I} \%$ \\
\hline $\mathrm{a})$ & 7 & 6,4 \\
\hline $\mathrm{b})$ & 6 & 5,5 \\
\hline $\mathrm{c})$ & 8 & 7,3 \\
\hline $\mathrm{d})$ resposta correta & 76 & 69,7 \\
\hline e) & 12 & 11,0 \\
\hline Total & $\mathbf{1 0 9}$ & $\mathbf{1 0 0 , 0}$ \\
\hline
\end{tabular}

Fonte: Dados da Pesquisa (2020)

Legenda: $\mathrm{Fi}$ = frequência, $\mathrm{Fl} \%=$ frequência percentual

De acordo com as normas adotadas no Brasil, o bem, que é objeto de arrendamento mercantil, deve ser contabilizado no ativo do arrendatário, no caso de leasing financeiro, e cerca de $70 \%$ dos profissionais identificaram como correta essa alternativa.

No que tange às normatizações acerca do arrendamento mercantil, o Pronunciamento Técnico CPC 06 determina como devem ser classificados esses arrendamentos. E questionados sobre isso, obtiveram-se os seguintes dados conforme Tabela 11: 
Tabela 11 - Classificação do arrendamento de um ativo conforme CPC 06

\begin{tabular}{c|c|c}
\hline Alternativas & $\mathbf{F i}$ & $\mathbf{F l \%}$ \\
\hline a) & 13 & 11,9 \\
\hline b) & 9 & 8,3 \\
\hline c) resposta correta & 68 & 62,4 \\
\hline d) & 7 & 6,4 \\
\hline e) & 12 & 11,0 \\
\hline Total & $\mathbf{1 0 9}$ & $\mathbf{1 0 0 , 0}$ \\
\hline
\end{tabular}

Fonte: Dados da Pesquisa (2020)

Legenda: $\mathrm{Fi}$ = frequência, $\mathrm{Fl} \%$ = frequência percentual

Da amostra da pesquisa, 68 profissionais acertaram ao marcar a alternativa que afirmava que, para a classificação das operações de arrendamento mercantil, nos termos do CPC 06, o arrendamento de um ativo é classificado como financeiro quando a natureza dos ativos arrendados for especializada, de tal forma que somente o arrendatário pode usá-los sem grandes alterações.

A Tabela 12 apresenta as informações pertinentes à questão que abordou sobre a modalidade pertinente à contabilização dos arrendamentos mercantis financeiros no arrendatário:

Tabela 12 - Modalidade de contabilização dos arrendamentos mercantis financeiros no arrendatário

\begin{tabular}{c|c|c}
\hline Alternativas & $\mathbf{F i}$ & $\mathbf{F I} \%$ \\
\hline a) resposta correta & 78 & 71,6 \\
\hline b) & 13 & 11,9 \\
\hline c) & 4 & 3,7 \\
\hline d) & 5 & 4,6 \\
\hline e) & 9 & 8,3 \\
\hline Total & $\mathbf{1 0 9}$ & $\mathbf{1 0 0 , 0}$ \\
\hline
\end{tabular}

Fonte: Dados da Pesquisa (2020)

Legenda: $\mathrm{Fi}$ = frequência, $\mathrm{Fl} \%$ = frequência percentual

As novas normas contábeis, convergentes ao padrão internacional, abordam a modalidade de como deverão ser contabilizados os arrendamentos mercantis financeiros no arrendatário, e, dentre essas modalidades, inclui-se que o arrendamento deverá ser apresentado no Ativo e no Passivo do Balanço e, aproximadamente, $72 \%$ da amostra marcaram essa modalidade como a correta.

A última questão do questionário abordou sobre o conceito de arrendamento mercantil, cujos dados foram dispostos na Tabela 13:

Tabela 13 - Conceito de arrendamento mercantil

\begin{tabular}{c|c|c}
\hline Alternativas & $\mathbf{F i}$ & $\mathbf{F l \%}$ \\
\hline a) & 9 & 8,3 \\
\hline b) & 12 & 11,0 \\
\hline c) resposta correta & 71 & 65,1 \\
\hline d) & 8 & 7,3 \\
\hline e) & 9 & 8,3 \\
\hline Total & $\mathbf{1 0 9}$ & $\mathbf{1 0 0 , 0}$ \\
\hline
\end{tabular}

Fonte: Dados da Pesquisa (2020)

Legenda: $\mathrm{Fi}$ = frequência, $\mathrm{FI} \%$ = frequência percentual

Ao dispor o fragmento da norma que afirma que "constitui-se o arrendamento que transfere substancialmente todos os riscos e benefícios inerentes à propriedade do ativo subjacente", 71 dos 109 profissionais contábeis associaram ao arrendamento financeiro, conforme o que determina a norma.

Após realizar toda análise de frequência de cada questão aplicada aos profissionais, buscou-se, também, comparar as notas obtidas por gênero. Para determinação da nota, cada questão certa valia 1,25; como foram 8 questões especificas e pertinentes ao objetivo do trabalho, totalizavam, então, 10 pontos se os respondentes acertassem todas as questões. A Tabela 14 apresenta a estatística descritiva, comparando as notas por gênero: 
Tabela 14 - Estatísticas Descritivas das Notas por Gênero

\begin{tabular}{l|c|c}
\hline & Nota para o sexo Feminino & Nota para o sexo Masculino \\
\hline $\mathrm{N}$ & 65 & 44 \\
\hline Média & 6,0000 & 6,1932 \\
\hline Mediana & 7,5000 & 7,5000 \\
\hline Moda & 8,75 & 8,75 \\
\hline Desvio Padrão & 3,12656 & 2,90292 \\
\hline Variância & 9,775 & 8,427 \\
\hline Mínimo &, 00 &, 00 \\
\hline Máximo & 8,75 & 10,00 \\
\hline \multicolumn{2}{|c}{}
\end{tabular}

De acordo com os dados obtidos através da estatística descritiva, percebeu-se que a média de nota do sexo feminino foi de 6 e do sexo masculino de 6,19. A nota máxima percebida pelo sexo feminino foi de 8,75 , que corresponde a 7 questões corretas; do sexo masculino, a nota máxima foi 10.

Com base nos dados acima, buscou-se, ainda, perceber se há diferença significativa entre as notas, por gênero, levando em consideração as questões de forma individual de acordo com a Tabela 15:

Tabela 15 - Estatísticas de teste

\begin{tabular}{l|r|r|r|r|r|r|r|r}
\hline & \multicolumn{1}{|c|}{$\begin{array}{c}\text { Q. 5 - } \\
\text { Nota }\end{array}$} & $\begin{array}{c}\text { Q. 6- } \\
\text { Nota }\end{array}$ & $\begin{array}{c}\text { Q. 7- } \\
\text { nota }\end{array}$ & $\begin{array}{c}\text { Q. 8 - } \\
\text { nota }\end{array}$ & $\begin{array}{c}\text { Q. 9- } \\
\text { nota }\end{array}$ & $\begin{array}{c}\text { Q. 10 - } \\
\text { nota }\end{array}$ & $\begin{array}{c}\text { Q. 11- } \\
\text { nota }\end{array}$ & $\begin{array}{c}\text { Q. 12- } \\
\text { nota }\end{array}$ \\
\hline U de Mann-Whitney & 1312,50 & 1327,00 & 1368,50 & 1215,50 & 1393,00 & 1296,50 & 1347,50 & 1411,50 \\
\hline Wilcoxon W & 3457,50 & 2317,00 & 3513,50 & 3360,50 & 2383,00 & 2286,50 & 3492,50 & 3556,50 \\
\hline Z & $-1,33$ &,- 82 &,- 47 & $-1,61$ &,- 28 &,- 98 &,- 65 &,- 13 \\
\hline $\begin{array}{l}\text { Significância Sig. (2 } \\
\text { extremidades) }\end{array}$ &, 18 &, 41 &, 63 &, 10 &, 77 &, 32 &, 51 &, 89 \\
\hline
\end{tabular}

Fonte: Dados da Pesquisa (2020)

Nota: Variável de agrupamento 1) Gênero.

Legenda: Q. = Questão.

O que se percebeu ao realizar a estatística de teste é que, em nenhuma das questões, apresentou-se correlação significativa entre a nota e o gênero, podendo afirmar, assim, que não houve diferença significativa nas notas, por gênero, ao analisar as questões individualmente, já que o nível de significância foi maior que 0,100 em todas as questões.

Averiguou-se, também, se existe correlação significativa entre o tempo de formação dos profissionais e a nota. Para que fosse possível realizar esse comparativo, teve que realizar, em princípio, o teste de normalidade conforme exposto na Tabela 16:

Tabela 16 - Teste de Normalidade

\begin{tabular}{|c|c|c|c|c|c|c|c|}
\hline & \multicolumn{3}{|c|}{ Kolmogorov-Smirnova } & \multicolumn{3}{|c|}{ Shapiro-Wilk } \\
\hline & & Estatística & $\mathrm{df}$ & Sig. & Estatística & $\mathrm{df}$ & Sig. \\
\hline $\begin{array}{l}\text { Tempo de } \\
\text { (anos) }\end{array}$ & Formação & 233 & 108 & ,000 & 674 & 108 & ,000 \\
\hline Nota & & ,249 & 108 &, 000 & 812 & 108 &, 000 \\
\hline
\end{tabular}

Nota: a. Correlação de Signifiância de Lilliefors

De acordo com o teste de normalidade, o valor de $p$ foi menor que o nível de significância, portanto deve-se rejeitar a hipótese nula, e conclui-se que os dados não seguem distribuição normal. Para tanto, utilizou-se um teste de correlação não paramétrico conforme Tabela 17: 
Tabela 17 - Testes de correlação não paramétricos Tau b de Kendall e R de Spearman

\begin{tabular}{|c|c|c|c|c|}
\hline & & & $\begin{array}{l}\text { Tempo de } \\
\text { Formação } \\
\text { (anos) }\end{array}$ & Nota \\
\hline \multirow[t]{6}{*}{$\overline{\text { tau_b de Kendall }}$} & \multirow{3}{*}{$\begin{array}{l}\text { Tempo de } \\
\text { (anos) }\end{array}$} & Coeficiente de Correlação & 1,000 & 053 \\
\hline & & Sig. (2 extremidades) & & 477 \\
\hline & & $\mathrm{N}$ & 108 & 108 \\
\hline & \multirow[t]{3}{*}{ Nota } & Coeficiente de Correlação & 053 & 1,000 \\
\hline & & Sig. (2 extremidades) & 477 & \\
\hline & & $\mathrm{N}$ & 108 & 109 \\
\hline \multirow[t]{6}{*}{ rô de Spearman } & \multirow{3}{*}{$\begin{array}{l}\text { Tempo de Formação } \\
\text { (anos) }\end{array}$} & Coeficiente de Correlação & 1,000 & 071 \\
\hline & & Sig. (2 extremidades) & & ,466 \\
\hline & & $\mathrm{N}$ & 108 & 108 \\
\hline & \multirow[t]{3}{*}{ Nota } & Coeficiente de Correlação & 071 & 1,000 \\
\hline & & Sig. (2 extremidades) & ,466 & \\
\hline & & $\mathrm{N}$ & 108 & 109 \\
\hline
\end{tabular}

Fonte: Dados da Pesquisa (2020)

Em ambos testes de correlação apresentados, o tempo de formação em anos e as notas dos profissionais no questionário não apresentaram correlação significativa, haja vista que o valor apresentado foi acima do nível de significância permitida, 0,477 e 0,466.

Ao verificar sobre a correlação entre as notas e a área da atuação, e realizar uma estatística de teste de Kruskal Wallis, observaram-se os seguintes dados:

Tabela 18 - Teste de Kruskal Wallis - Notas versus Área de Atuação

\begin{tabular}{l|r}
\hline & \multicolumn{1}{|r}{ Nota } \\
\hline Qui-quadrado & 4,745 \\
\hline Df & 2 \\
\hline Significância Sig. &, 093 \\
\hline
\end{tabular}

Fonte: Dados da Pesquisa (2020)

Notas: Teste Kruskal Wallis; Variável de Agrupamento: Atuação.

Não houve diferença significativa nas notas por área de atuação dos profissionais contábeis, isso acaba dando ênfase que, independente da área da atuação, os profissionais precisam buscar, cada vez mais, uma educação continuada e atualizações acerca de sua profissão, para, assim, se manter no mercado de trabalho.

Acerca da pesquisa realizada, sabe-se que a lei não atingiu de maneira completa em todas as organizações, nem todos os profissionais sentiram o impacto dessa lei. Diante dessa situação, A IFRS 16, que entrou em vigor $1^{\circ}$ de janeiro de 2019, ainda permite um período de adaptação e de uma análise prévia do impacto que a contabilização do leasing operacional causará na instituição.

A obrigação de todas as empresas seguirem o IFRS ocorre de maneira indireta. No caso de pequenas e médias, não será necessário seguir a versão completa do IFRS, que possui mais de 2,5 mil páginas. O CPC traduziu um pronunciamento específico do Conselho de Normas Internacionais de Contabilidade para empresa de menor porte, que contém 225 páginas.

Observa-se que as respostas diferem, ou seja, não há um entendimento comum em relação aos benefícios trazidos pela norma IFRS 16; isso comprova a falta de real entendimento das mudanças e objetivos trazidos pela adoção às IFRS. Em virtude das alterações ocorridas na contabilidade, torna-se ainda mais necessária essa atualização por parte dos profissionais contábeis.

Grande parte dos profissionais que participaram da pesquisa ainda não possui um bom nível de conhecimento acerca do assunto abordado. $\mathrm{O}$ índice de profissionais que conhecem o assunto é pequeno, embora estejam relacionados a um certo conhecimento; este não se apresenta de forma expressiva, podendo indicar que, proporcionalmente, os respondentes possuem, apenas, um ínfimo conhecimento sobre o assunto. $\mathrm{O}$ fato de o processo de adaptação da norma ainda estar em andamento e a todo o momento serem disponibilizadas novas informações pode justificar os números encontrados, ou a falta de interesse dos profissionais em buscar atualização profissional. 


\section{CONSIDERAÇÕES FINAIS}

O objetivo desta pesquisa foi investigar o nível de conhecimento da IFRS 16 pelos profissionais contábeis, utilizando uma pesquisa descritiva, em que se utilizou, como instrumento de pesquisa, um questionário aos profissionais e, através dos dados obtidos, observar se houve correlação entre dados como tempo de formação, tempo de atuação, entre outros.

De acordo com os dados apurados na pesquisa, percebeu-se que os contadores ainda não possuem conhecimento suficiente sobre as IFRS, já que, de acordo com as respostas, não houve entendimento comum entre os profissionais de contabilidade ao serem questionados sobre aspectos básicos da IFRS 16.

O contador deve ser um profissional que tenha visão sistêmica da empresa, pois sua atuação exige que conheça as operações realizadas, faça seu registro e apresente as informações resultantes do processo contábil na forma de relatórios para a administração da empresa, a fim de que esta possa tomar decisões. As decisões tomadas, por sua vez, podem ocasionar retornos positivos ou negativos para a empresa e influenciar quem dela depende. Nessas circunstâncias, o contador assume, verdadeiramente, uma responsabilidade social.

O mercado de trabalho está mudando, sendo necessário que o profissional contábil conheça essas novas mudanças, pois hoje não basta, apenas, atender às necessidades práticas. É preciso que o contador do século XXI preste informações precisas, dando perfeitas condições aos empresários de como comandar com segurança as suas atividades econômicas. O contador necessita atender às expectativas voltadas a habilidades empreendedoras.

Constatou-se, ainda, que os profissionais da contabilidade atuais, respeitando as limitações da amostra, não estão plenamente preparados em termos de conhecimento para atender às exigências do mercado. Cabe a cada um deles buscar fontes de aprendizagem, manter-se atualizado para poder suprir as necessidades das entidades, uma vez que o contabilista será cada vez mais valorizado diante da globalização e do crescimento econômico do País.

O estudo permitiu identificar que os profissionais precisam se atualizar constantemente, haja vista que as Normas de Contabilidade passam por mudanças que afetam, diretamente, a adoção dos procedimentos; e assim a formação, no curso superior, deve ser sempre continuada, com cursos que abordem as principais mudanças que devem ser aplicadas no dia a dia do profissional contábil.

Quanto às limitações encontradas durante a pesquisa, destaca-se o interesse em conhecer a percepção dos contadores de outras regiões. Além disso, houve dificuldade em conseguir que todos os profissionais que receberam os questionários, através de formulários online, respondessem, tornando, assim, limitada a amostra pesquisada.

Por se tratar de um assunto atual e relevante para a Contabilidade, ainda há muito que se discutir sobre o tema, por isso, sugere-se: realizar uma pesquisa em outros estados, permitindo, assim, comparações sobre o nível de conhecimento por parte dos profissionais; outra oportunidade de pesquisa seria verificar como a implantação das Normas Internacionais de Contabilidade influencia nos resultados anuais das empresas.

\section{REFERÊNCIAS}

ARAUJO, T. A.; ZITTEI, M. V. M. Impactos na convergência das Normas Internacionais de Contabilidade de Leasing para arrendatários. Cafi, v. 1 n. 1, p. 44-57. 2018.

BECKER, D. C. C. Os impactos contábeis na adoção inicial dos CPCs nas empresas de grande porte do Brasil no seguimento de telecomunicações. Redeca, v. 4, n. 1. 2017.

BRASIL. Comissão de Valores Mobiliários. Deliberação n. 539, de 14 de março de 2008. Aprova o pronunciamento conceitual básico do CPC que dispõe sobre a estrutura conceitual para a elaboração e apresentação das demonstrações contábeis. DOU, DF, 14 mar. 2008.

CAMPANHA, R. A.; SANTOS, O. M. Impactos da adoção do IFRS 16 em uma empresa brasileira arrendatária. Revista enfoque e reflexão contábil, v. 39, n. 3, p. 1-18, set./dez. 2020.

COSTA, C. L.; CAMPOS, F. M.; AMARAL, M. M. Capacitação Profissional: um estudo sobre a adoção das normas internacionais de contabilidade (IFRS) nas instituições particulares de ensino superior do ABC. Revista Brasileira de Contabilidade, Brasília, n. 177, p. 77-89, maio/jun. 2009.

CRUZ, A. P. C.; MACHADO, E. A.; PEREIRA, A. F.; CARVALHO, L. N. Empresas brasileiras do novo mercado e suas práticas de evidenciação voluntária de informações por segmento. In: Congresso ANPCONT, 5, 2011, Vitória, Anais... São Paulo: ANPCONT, 2011.

DANTAS, J. A.; MICHELETTO, M. A.; CARDOSO, F. A.; FREIRE, A. A. P. F. S. Perdas em crédito nos bancos brasileiros: modelo de perdas esperadas e de perdas incorridas e impactos da IFRS 9. Revista gestão, finanças e contabilidade, v. 7, n. 2, maio/ago, p. 156-175. 2017.

DANTAS, J. A.; RODRIGUES, F. F.; NIYAMA, J. J.; MENDES, P. C. M. Normatização contábil baseada em princípios ou 
em regras? Benefícios, custos, oportunidades e riscos. Revista de Contabilidade e Organizações, v. 4, n. 9, p. 3-29. 2017.

FONTELES, I. V.; OLIVEIRA, M. C.; ALMEIDA, S. R. Medidas adotadas pelas IFES brasileiras visando a qualificação docente e a adequação de conteúdos com as novas práticas contábeis. In: Congresso USP de Iniciação Científica, 8. , 2011, São Paulo, Anais... São Paulo: USP Iniciação Científica, 2011.

GIROTTO, M.; NASCIMENTO, L, S. Representante do Brasil no International Public Sector Accounting Standards Board (IPSASB). Revista Brasileira de Contabilidade, v. 10, n. 5. 2017.

GONÇALVES, M. N.; SANCHES, S. L. R. Disclosure x sustentabilidade: um estudo das demonstrações contábeis das companhias listas pela Brazil Stars Index. Revista TCEMG, v. 34, n. 4, p. 42-57, out./dez. 2016.

INTERNACIONAL ACCOUNTING STANDARDS BOARD - IASB. International Financial Reporting Standards (IFRS) 16. 2016. Disponível em: < http://www.cpc.org.br/CPC/Documentos-Emitidos/Pronunciamentos/Pronunciamento?ld=37>. Acesso em: 05 jun. 2020.

MATOS, N. B.; NIYAMA, J. K. IFRS 16 - Leases: Desafios, Perspectivas e Implicações à Luz da Essência Sobre a Forma. Revista de Educação e Pesquisa Em Contabilidade (REPeC), n. 12, v. 3, jul./set. 2018.

MEIRELLES, W.; VENDRUSCOLO, M. I. Impactos da internacionalização da contabilidade em uma companhia de óleo e gás da Rússia. Revista de Administração e Contabilidade, v. 16, n. 32, p. 103-119, jul./dez. 2017.

NIYAMA, J. K. Contabilidade internacional. São Paulo: Atlas, 2009.

RIBEIRO, C. W. L. Adoção das normas IFRS no âmbito mundial e o seu impacto na comparabilidade das demonstrações contábeis. RAGC, v.5, n.21, p.87-97. 2017.

SILVA, R. L. M. Adoção completa das IFRS no Brasil: qualidade das demonstrações contábeis e o custo de capital próprio. 2013. Tese (Doutorado em Controladoria e Contabilidade: Contabilidade) - Faculdade de Economia, Administração e Contabilidade, Universidade de São Paulo, São Paulo, 2013.

TAY, J. S. W.; PARKER, R. H. Measuring International Harmonization and Standardization. Abacus, Sydney, v. 26, p. 7188, 1990.

ZORTEA, C. T.; GALDI, F. C.; MONTE-MOR, D. S.; BEIRUTH, A. X. Eficiência do mercado de capitais após a adoção da IFRS no Brasil: aplicando o teste de Mishkin. Revista contemporânea de contabilidade, v. 14, n. 32, p. 141-156, maio/ago. 2017. 


\section{APÊNDICE \\ APÊNDICE A \\ QUESTIONÁRIO \\ QUESTIONÁRIO - IFRS 16}

*Obrigatório

Endereço de e-mail *

Seu e-mail

O presente questionário tem por objetivo apontar o nível de conhecimento e aplicação da IFRS 16 pelos profissionais contábeis de Pernambuco. Portanto, a abordagem apresentada garante o sigilo de dados pessoais, de forma que não serão divulgados dados individuais, apenas o tratamento em geral.

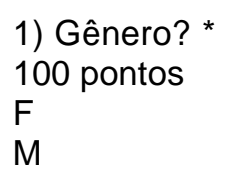

2) Tempo de profissão? *

100 pontos

2 a 4 anos

5 a 7 anos

8 a 10 anos

11 anos acima

3) Ano de formação? *

100 pontos

Sua resposta

4) Atuação? *

100 pontos

Sócio empresa/escritório contábil;

Autônomo;

Responsável/empregado(a) de área contábil;

5) Como é feita a contabilização do contrato utilizando a norma de Arrendamento IFRS 16 ? * 125 pontos

a) Pode abranger custos de benfeitorias feitas em bens alugados;

b) A empresa deve reconhecer o ativo de direito de uso, bem como o passivo de arrendamento;

c) O passivo de arrendamento deve ser mensurado pelo valor presente dos pagamentos do arrendamento;

d) O passivo deve ser segregado em circulante e não circulante;

e) Não sei responder.

6) A operação de arrendamento mercantil que transfere ao arrendatário substancialmente todos os riscos inerentes ao uso do bem arrendado,como obsolescência tecnológica, desgastes, etc, denomina-se: * 125 pontos

a) Arrendamento Mercantil Operacional;

b) Arrendamento Mercantil Financeiro;

c) Arrendamento Mercantil Não Cancelável;

d) Leasing Operacional;

e) Não sei responder.

7) Como deverão ser contabilizados as contraprestações dos contratos de arrendamento mercantil operacional na escrituração contábil do arrendatário? *

125 pontos

a) Conta redutora do passivo;

b) Diretamente em resultado;

c) Em despesas antecipadas; 
d) Baixar o valor registrado no passivo;

e) Não sei responder.

8) Em um arrendamento mercantil financeiro, o valor residual garantido consiste: *

125 pontos

a) Na parcela do valor residual do bem arrendado que seja garantida pelo arrendatário ou por alguém a ele relacionado ao arrendador;

b) No valor pelo qual um ativo pode ser negociado, ou um passivo liquidado, entre partes interessadas, conhecedoras do negócio e independentes entre si;

c) Na parcela dos pagamentos do arrendamento mercantil que não seja de quantia fixada, e sim baseada na quantia futura de um fator que se altera sem ser pela passagem do tempo;

d) No valor de mercado do bem;

e) Não sei responder.

9) De acordo com as normas internacionais de contabilidade, adotadas pela contabilidade brasileira, o bem objeto de arrendamento mercantil deve ser contabilizado no: *

125 pontos

a) Ativo do arrendador, no caso de leasing financeiro;

b) Ativo do arrendatário, no caso de leasing operacional;

c) Passivo do arrendatário, independentemente da modalidade do arrendamento;

d) Ativo do arrendatário, no caso de leasing financeiro;

e) Não sei responder.

10) A classificação das operações de arrendamento mercantil, nos termos do Pronunciamento Técnico CPC 06 , o arrendamento de um ativo é classificado como financeiro quando o(a): *

125 pontos

a) Valor presente dos pagamentos mínimos do arrendamento totalizar uma pequena parte do valor justo do ativo arrendado;

b) Arrendatário tem a opção de compra do ativo por valor igual ao seu valor justo, na data em que a opção se torne exercível;

c) Natureza dos ativos arrendados for especializada, de tal forma que somente o arrendatário pode usálos sem grandes alterações;

d) Prazo do arrendamento corresponder à maior parte da vida econômica do ativo, mas somente quando há transferência da propriedade;

e) Não sei responder.

11) As novas normas contábeis, convergentes ao padrão internacional, abordam a modalidade de como deverão ser contabilizados os arrendamentos mercantis financeiros, no arrendatário. A alternativa que apresenta um dos aspectos dessa modalidade é: *

125 pontos

a) O arrendamento deverá ser apresentado no Ativo e no Passivo do Balanço;

b) As contraprestações deverão ser contabilizadas diretamente em resultado;

c) Os juros do contrato deverão ser reconhecidos em uma base trimestral;

d) Os itens desse tipo de contrato não devem ser depreciados;

e) Não sei responder.

12) Arrendamento Mercantil, identifica-se o seguinte conceito associado aos arrendamentos: "Constitui-se o arrendamento que transfere substancialmente todos os riscos e benefícios inerentes à propriedade do ativo subjacente". Esse fragmento faz referência ao: *

125 pontos

a) Ativo de direito de uso;

b) Arrendamento operacional;

c) Arrendamento financeiro;

d) Arrendamento de curto prazo;

e) Não sei responder. 
